\title{
Veinticinco años de arqueología urbana en Mérida
}

\author{
Rosalía-María Durán Cabello (Universidad Autónoma de Madrid) \\ F. Germán Rodríguez Martín (Arqueólogo)
}

\section{Resumen}

En este artículo queremos poner de relieve el profundo cambio registrado en la Arqueología emeritense a lo largo del s. XX, y especialmente en el último cuarto de siglo, subrayando el paso de una arqueología de sondeos dispersos, sin método ni criterios unificados, a la actual en la que todas las intervenciones están perfectamente coordinadas gracias a la asunción de la idea de que Mérida es un yacimiento unitario, en el que las actuaciones arqueológicas han de seguir un único criterio basado en una acción integrada, integradora y positiva. Las directrices actuales abarcan todos los pasos de la realidad arqueológica: desde el método de excavación, pasando por documentación, investigación, difusión así como criterios de conservación y puesta en valor. Todo ello redunda en un mejor y más completo conocimiento de las diversas "Méridas" históricas.

Palabras clave: arqueología urbana, sondeo, excavación sistemática, excavación de urgencia, publicación de resultados.

\section{Abstract}

Dans cet article nous voulons mettre de relief le profond changement déposé dans l'Archéologie emeritense tout au long du s. XX, et particulièrement dans le dernier quart de siècle, soulignant le pas d'une archéologie de sondages dispersés, sans méthode ni critères unifiés à l'actuel dans laquelle toutes les actions sont parfaitement coordonnées grâce à la prise en charge de l'idée de que Mérida est un gisement unitaire en le que les conduites archéologiques doivent suivre un unique critère fondé en une action intégrée, intégratrice et épreuve positive. Les directrices actuelles embrassent tous les pas de la réalité archéologique: depuis la méthode d'excavation, passant par documentation, investigation, diffusion ainsi que critères de conservation et coucher en valeur. Tout cela déborde en un meilleur et plus complète connaissance des différents "Méridas" historiques.

\section{INTRODUCCIÓN}

La ciudad de Mérida ha debido convivir desde siempre con el hecho de ocupar un solar que desde el año 25 a. C. había sido la colonia romana de Augusta Emerita, capital de Lusitania; en el s. IV d.C., capital de la diocesis Hispaniarum; entre los siglos VI y VII d.C. fue sede visigótica, antes de estar bajo dominio musulmán. La necesidad de convivencia con el legado arqueológico sale al paso de sus habitantes no sólo cuando deambulan por su ciudad, sino que aflora cada vez que deben acometer cualquier obra de la índole que ésta sea.

Desde antiguo tenemos noticias del interés que suscitaban las ruinas entre los propios eme- ritenses, así como en los eruditos de la época, ya desde el s. $\mathrm{XV}^{1}$ y aún antes ${ }^{2}$. Sin embargo, la actitud de los emeritenses contemporáneos ante esta situación ha variado a lo largo del s. XX. En efecto, a comienzos del pasado siglo se comenzó a exhumar con verdadero interés científico, primero el teatro ${ }^{3}$, y después el anfiteatro. La excavación de este área no pudo finalizarse debido a la irrupción de la guerra civil. Hasta la guerra civil, las excavaciones ${ }^{4}$ se centraron principalmente en el conjunto monumental de teatroanfiteatro.

Una vez finalizada la guerra se abre un periodo largo en el que lo más destacable es la apatía respecto a la conservación del Patrimonio Arqueológico. En esta época aún no se tiene conciencia de lo que hoy entendemos como 
"Arqueología urbana", ya que esta se origina -más o menos- en la década de los setenta del pasado siglo, puesto que el problema de las ciudades infrapuestas se agudiza con el desarrollismo de estos años.

A mediados de los setenta, concretamente en 1975, tiene lugar en Mérida la celebración del Congreso Conmemorativo del Bimilenario de la Fundación de la ciudad. Constituye un auténtico hito tanto científico - puesto que se trata del estado de la cuestión en aquél momento-, como historiográfico y teórico. Mérida es concebida como una realidad arqueológica unitaria, aunque solamente para el periodo hispanorromano. Esto último, sin duda, es reflejo de la profunda transformación que desde el punto de vista metodológico y conceptual se estaba produciendo en la comunidad científica de la época (Fernández Ochoa y Durán Cabello, 2006).

En este lento pero inexorable proceso de cambio incide sin duda, positivamente, la nueva situación creada tras la transición hacia un sistema democrático. La transferencia de las competencias en materia de Patrimonio Histórico a las recién creadas Comunidades Autónomas y la aprobación de la Ley de Patrimonio de 1985 abren nuevas perspectivas en el campo de la arqueología española y Mérida no se queda al margen de esta transformación.

Como consecuencia de aplicar la Ley de Patrimonio Histórico Español de 1985, la Arqueología Urbana se desarrolla muy notablemente, aportando datos que nos permiten tener un mayor conocimiento del pasado de Mérida. Esto es debido no sólo a la articulación legal, sino también a la planificación y unificación del sistema de recuperación de datos arqueológicos y a la labor paciente, tenaz y minuciosa de los arqueólogos que allí trabajan. En este artículo pretendemos esbozar como se han ido desarrollando los trabajos arqueológicos en algo más de un cuarto de siglo -desde 1975 hasta nuestros días-, y su repercusión en el campo de la investigación científica.

\section{Precedentes de la arQuelogía URBANA EMERITENSE}

Antes de abordar el tema es necesario realizar un breve bosquejo del devenir de la arqueología emeritense una vez finalizada la guerra civil, ya que es fundamental para comprender la causa de las actuaciones posteriores.

Los últimos años de los trabajos de D. José Ramón Mélida y D. Maximiliano Macías se centraron en terminar de excavar el teatro, concretamente en el área de la porticus postscaenam y el peristylium, así como las necrópolis sitas extramuros de la ciudad -zona $\mathrm{S}$ y $\mathrm{SE}^{6}$-. Dado lo avanzado de la edad de ambos investigadores, fue un discípulo de Mélida el que se hizo cargo de las mismas, D. Antonio Floriano Cumbreño. De hecho, Mélida y Macías mueren en 1933 y 1934, respectivamente, y Floriano fue nombrado responsable de las excavaciones del conjunto arqueológico, por parte de la Junta Superior del Tesoro Artístico, en el año 1934. Entre esta fecha
1 En concreto nos referimos León de Rosmithal de Blatna, quien en el s. XV hace referencia genérica a las ruinas de la ciudad, precisando que Roma creó y destruyó varias veces Mérida (García Mercadal, 1952, 980; Durán Cabello, 2004, 18). Sin embargo, los datos más importantes que poseemos nos son transmitidos por Antonio de Nebrija. Se trata de un poema inspirado en las ruinas de Mérida y que tituló De Emerita Restituta, parangonable al que Rodrigo Caro dedicó a las Ruinas de Itálica. Aunque no conocemos la fecha exacta en la que se escribió, sí sabemos que fue anterior a 1491, año en que fue publicada por el bachiller Vivanco en Salamanca. Como muy bien señala Álvarez Sáenz de Buruaga, Nebrija se muestra como un auténtico conocedor del solar emeritense e incluso llegó a realizar estudios en el circo investigando sobre el tamaño del antiguo pie hispano (Álvarez Sáenz de Buruaga, 1950, 8). El hecho de que iniciase un estudio referido al pie hispano lo consideramos de suma importancia por lo revelador de las inquietudes científicas del momento.

2 No es este el momento ni el lugar de hacer una exhaustiva enumeración de las noticias aportadas en fechas anteriores aunque a modo de ejemplo cabe señalar el interés que suscitaron las ruinas de Emerita entre los geógrafos musulmanes como son los casos de Al-Idrisi, en 1154 o, posteriormente, ya en el s. XIV, las referencias aportadas por Ismael Imad-ab-Din-al-Ayubi, más conocido como Abulfeda (Álvarez Sáenz de Buruaga, 1958, 564-565; Durán Cabello, 2004, 18).

3 Sabemos que el teatro, por sus características constructivas, se convirtió desde temprano en improvisada cantera para realizar ciertas construcciones y reparaciones, como lo pone de manifiesto Bernabé Moreno de Vargas (Moreno de Vargas, [1633],1987, 81-82; Durán Cabello, 2004, 19;).

4 En estas mismas décadas se excavaron áreas funerarias, como los "bodegones" y los llamados columbarios.

5 Actualmente se concibe la Arqueología Urbana como un proyecto integral de investigación arqueológica cuya finalidad es desvelar la historia de la ciudad a lo largo del espacio y del tiempo, concibiendo la ciudad como un único yacimiento que puede tener múltiples superposiciones (Fernández Ochoa y Querol, 2000, 12; Fernández Ochoa y Durán Cabello, 2006)

6 Concretamente los denominados "bodegones" así como diversas tumbas tanto de inhumación como de incineración rastreadas y excavadas en los alrededores del antiguo cuartel de Artillería y aledaños del circo romano. Hay que destacar la excavación de un columbario en el área vecina al anfiteatro, por el este (Floriano Cumbreño, 1944, 161-172; fig. 5 y 9). 
y 1936 realiza tres campañas en el pórtico del teatro, y una cuarta, de consolidación, tras los estragos de la guerra (Floriano Cumbreño, 194041, 445; ídem, 1944, 151-153).

Desde el fin de la contienda, y hasta 1962, el Director de las Excavaciones de la ciudad fue D. José de Calasanz Serra Ráfols. Aunque apenas hace intervenciones, debemos destacar la que realiza en la Alcazaba (Serra Ráfols, 1946, 334345). En 1943 es designado, temporalmente, director del Museo de Mérida y responsable de las intervenciones arqueológicas, D. José Álvarez Sáenz de Buruaga. En Mérida desarrolla su labor hasta 1945, año en que regresa a Madrid y es sustituido por D. Octavio Gil Farrés. Con éste permutará su plaza madrileña, para quedar definitivamente establecido en la ciudad, al frente del museo y de casi todas las excavaciones.

A partir de 1962 es nombrado Comisario de Zona del Patrimonio Artístico, D. Martín Almagro Basch, aunque este dirigía las excavaciones desde Madrid. Por estas fechas, y bajo su mandato, se inician las tareas de limpieza y anastilosis del frente escénico del teatro y del peristilo, y se finaliza el vaciado de algunos vomitoria del anfiteatro (cuarto suroeste). Este proceso se hace bajo la dirección de D. José MenéndezPidal, y con la supervisión arqueológica de D. Alejandro Marcos Pous ${ }^{8}$. De hecho, bajo la dirección de Marcos Pous se excavó una tumba bajo uno de los frogones del graderío del anfiteatro (Marcos Pous, 1961), hallazgo que hasta nuestros días no ha sido valorado en toda su dimensión (Bendala y Durán, 1995, 255-256; Durán Cabello, 2004, 213-215; Rodríguez Martín, 2003).

En 1962 D. Eugenio García Sandoval llega a Mérida de la mano de D. G. Nieto Gallo y se hace responsable de lo que hoy denominaríamos "excavaciones de urgencia de la ciudad". En palabras de Álvarez Martínez, García Sandoval se limitó a resolver “(...) mil problemas diarios enfocados al salvamento de las venerables ruinas emeritenses" por lo que "... se limitó (...) a la lucha diaria que caracterizaba a los profesionales de entonces" (Álvarez Martínez, 1996, 9). Pero García Sandoval, también acometió excavaciones sistemáticas entre

7 Es este uno de los pocos datos que hacen referencia, aunque sea muy vaga, a los daños que debieron padecer los monumentos durante la contienda.

8 En el mismo periodo en que trabajó Marco Pous en Mérida, también participó en las tareas arqueológicas el escultor Juan de Âvalos.

9 No debemos olvidar que en estas fechas no existía ninguna ley de rango local ni nacional que regulase las intervenciones que se practicasen en los cascos urbanos histó- los años 1964 y 1968 en la llamada "Casa del Anfiteatro" y en la "Casa del Mitreo" (García Sandoval, 1966 y 1969 a y b). En esta última se descubrió el magnífico mosaico cosmogónico (García Sandoval, 1969 b).

En 1963 nace un organismo decisivo para la arqueología emeritense: el Patronato de la Ciudad Monumental Histórico-Artística y Arqueológica, cuyo secretario fue D. José Álvarez Sáenz de Buruaga. La creación del Patronato, que contaba con el respaldo del Ayuntamiento de la ciudad, supone un paso decisivo en favor de la salvaguarda del Patrimonio Arqueológico Emeritense, puesto que se hizo responsable de la supervisión tanto de las obras de infraestructura que se realizaban en la ciudad, como de las excavaciones sistemáticas que se acometieron en esos años, y a las que aludiremos más adelante. Las intervenciones eran supervisadas por Álvarez Sáenz de Buruaga, auxiliado por D. Antonio Díaz Pintiado.

Por último, hay que señalar que el Patronato acometió una política de expropiaciones destinadas tanto a la protección del Patrimonio Arqueológico como a su puesta en valor, integrando los restos en viario de la ciudad. Asimismo fue ejemplar su sorprendente "modernidad" en cuanto a autogestión y autofinanciación se refiere (Velázquez Jiménez, 1996, 352; Fernández Ochoa y Durán Cabello, 2006, 126).

Como se puede ver, la creación del Patronato redundó en mejores resultados de documentación y protección del Patrimonio Arqueológico emeritense. Prueba de ello es una tendencia a centralizar en Mérida todo tipo de responsabilidades. Así, a finales de los sesenta, concretamente en 1969, Álvarez Sáenz de Buruaga toma el relevo del Comisariado de Excavaciones de Mérida, por un periodo de 10 años.

Ante la proliferación de las obras en la ciudad - no olvidemos que estamos en los años del desarrollismo-, y la dificultad de supervisar todas las intervenciones sin poder evitar que alguna se hiciera sin control arqueológico, se creó en 1971 la Comisión Local de Defensa del Patrimonio. Dicho organismo articuló una normativa para procurar la salvaguarda de los restos arqueológi-

ricos, por lo que los arqueólogos debían realizar, además, una labor casi detectivesca para encontrar las obras y revisarlas, ya que era una práctica muy extendida que se realizasen dichas remociones a escondidas para evitar así cualquier retraso en la ejecución de dichas obras. Así que en el mejor de los casos, se procedía a tomar nota de los hallazgos y se recogían los materiales muebles más significativos. 
cos que ofrecía constantemente la ciudad ${ }^{9}$. Al año siguiente, esta medida se vio implementada con el decreto de 8 de febrero de 1972 por el cual se declaraba a la ciudad de Mérida Conjunto Histórico, Artístico y Arqueológico (Álvarez Martínez, 1985, 44; Fernández Ochoa y Durán Cabello, 2006, 126).

Bajo la responsabilidad del Patronato se acometieron, además, sondeos y excavaciones de tipo sistemático, entre las que habría que destacar, por su interés, las de la construcción interpretada como castellum aquae, en 1971 (Álvarez Martínez, 1977, 53-54); las del llamado Templo de Diana, entre 1972 y 1973 (Álvarez Martínez, 1973, 1973b; 1977b); así como las intervenciones realizadas en el circo romano en 1973 (Álvarez Sáenz de Buruaga y Álvarez Martínez, 1977, 100103). En 1970, durante la supervisión de unas obras por parte de Álvarez Sáenz de Buruaga, se descubrió y excavó una domus en la calle Suárez Somonte, cuyas pinturas fueron rescatadas, siendo en la actualidad visitables en el Museo Nacional de Arte Romano (Álvarez Sáenz de Buruaga, 1974), también se excavaron parte de los baños de la domus sita en el interior de la Alcazaba (Barrientos, 1977, 263).

Queremos destacar el interés que la antigua Emerita empieza a suscitar, a partir de los setenta, entre los investigadores internacionales. En efecto, en 1973, el arqueólogo francés Mr. Robert Lequement realiza unos sondeos estratigráficos en la Casa del Mitreo y en los llamados Columbarios (Lequement, 1978). Otros dedicarán estudios a los materiales emeritenses, especialmente la epigrafía y la cerámica. Gracias a trabajos como los de Mme. Françoise Mayet (1970) comienza a conocerse la riqueza conservada en los fondos del Museo de Mérida, a la sazón todavía repartido entre el antiguo Museo y la Alcazaba. Este es, grosso modo, el esbozo del devenir de la arqueología emeritense hasta llegar al punto de inflexión que hemos situado en 1975.

\section{EL BIMILENARIO DE LA FUNDACIÓN DE MÉRIDA}

Como hemos expuesto al principio, la celebración del Bimilenario de la ciudad tuvo una importante faceta científica, como fue la celebración de un congreso en esa ciudad en noviembre de 1975. En dicha reunión participaron todos los investigadores que en aquél momento estaban trabajando sobre Emerita. En esas ponencias, en líneas generales, se esbozaba un estado de la cuestión sobre la investigación arqueológica de esta ciudad. Se abordaron temas relativos a urbanismo, arquitectura, mundo funerario, pintura, escultura, mosaicos, población y restauración de los monumentos, entre otros temas (Augusta Emerita, 1975). Fruto de esta reunión científica fue la elaboración de un plan sistemático de actuación, cuya finalidad era aportar luz a los múltiples interrogantes que estaban abiertos y cuya realidad había sido convenientemente subrayada en el mencionado coloquio. Por ello, se tomó como objetivo prioritario la cuestión urbanística de Emerita, intentando esclarecer problemas como, por ejemplo, la cuestión de la muralla, de la que debía dilucidarse su trazado, su cronología, etc. También se convierte en tema prioritario de investigación el relativo a las áreas forales, de las que ya se conocía el foro local situado en la calle Sagasta, al tiempo que se hacen los primeros planteamientos sobre la posible localización del foro provincial en la calle Holguín, aunque aún faltaba mucho para su exhumación.

En esta nueva etapa las excavaciones sistemáticas están enfocadas a esclarecer los temas que acabamos de señalar. Al frente de las excavaciones se encontraba, desde 1979, Álvarez Martínez, y bajo su dirección se practicaron numerosas intervenciones.

Antes de proseguir, debemos subrayar un dato muy significativo a nuestro entender. A pesar de documentar y rescatar los materiales muebles y las estructuras de gran envergadura adscribibles al período hispanorromano, esta labor de exhumación y recuperación de vestigios se circunscribía a los límites del casco urbano y puntualmente, a su entorno inmediato. Si revisamos la bibliografía, observaremos lo escueto de los datos aportados por la arqueología urbana sobre otros periodos crono-culturales, ya sean prerromanos o medievales -tanto islámicos como cristianos-. Es consecuencia directa del desinterés que provocaban dichas facies entre los excavadores de la época, orientados desde un punto de vista ideológico, hacia la recuperación de la Emerita de Dion Cassio. El fenómeno no es una peculiaridad privativa de la arqueología emeritense, sino que también se ha constatado en otras ciudades superpuestas, como ocurre, por ejemplo, en el caso de Córdoba, donde los esfuerzos se centraban en la Corduba hispanorromana, mientras que del periodo andalusí sólo se recuperaba el material mueble, y no se documentaba de ninguna manera el resto de las edificaciones, so pretexto de su endeble constitución (Fernández-Ochoa y Durán Cabello, 2006, 125; Vicent y Pous, 1985, 235-236), lo que no dejaba de ocultar un posicionamiento ideológico y metodológico también muy claro.

Durante estos años se acometen diversas excavaciones, unas de mayor entidad, como son 
las de edificios y espacios públicos, y otras, de gran interés, aunque de menor relevancia, entre las que se incluyen los restos de edificaciones privadas. Muchas de las primeras se iniciaron con carácter sistemático. Dentro del primer apartado, e incluido en el epígrafe de excavaciones sistemáticas, aparecen los casos del teatro, anfiteatro y muralla.

En 1979, se emprendió bajo la dirección de Álvarez Martínez una campaña de excavaciones en el sector oriental del anfiteatro, con el fin de verificar el recorrido de la muralla por esta parte de la ciudad. Dicha memoria está en curso de publicación, pero parte de los resultados aparecen recogidos por D. José Ángel Calero Carretero en su memoria de licenciatura y en un artículo sobre la muralla y el anfiteatro de Mérida (Calero Carretero, 1986 y 1992). Al año siguiente, 1980, se acometió el descubrimiento del ángulo noroeste del peristylium del teatro, trabajo que no llegó a concluirse, pues aún falta por exhumar la esquina del pórtico (Álvarez Martínez, 1985, 42-43) ${ }^{10}$. También se incluyen en este apartado las dos campañas llevadas a cabo durante los años 1985 y 1986 en el Templo de Diana, a cargo de Álvarez Martínez (1991, 2003).

Respecto a las excavaciones de urgencia de estos años, debemos reseñar las acometidas en lo que luego se identificó como el pórtico del Forum Coloniae, así como el de un gran edificio público que se viene identificando como posible Capitolium por su situación y monumentalidad ${ }^{11}$.

Perteneciente también al apartado de excavaciones sistemáticas, e incluida en el epígrafe de edificios privados, contamos con la intervención realizada entre los años 1979 y 1980 en la Casa de la Torre del Agua ${ }^{12}$.

De "excavación preventiva" puede definirse la actuación practicada en el solar del entonces futuro Museo Nacional de Arte Romano, en la primera mitad de los ochenta. En estos trabajos se descubrió un tramo del specus del acueducto de San Lázaro, restos de varias domus suburbanas y parte de una calzada (Sánchez Sánchez y Nodar Becerra, 1997, 374-376). ${ }^{13}$

10 Las memorias de estos trabajos están aún en curso de estudio, aunque sí han adelantado algunos datos mediante artículos.

11 Ambas intervenciones arqueológicas están en curso de estudio. En el año 2002 se han practicado excavaciones por parte del Consorcio. Sobre el Templo de Diana se ha presentado recientemente una monografía, en la que se hace un estudio formal del edificio (Álvarez Martínez y Nogales Basarrate, 2003).

\section{EL TRASPASO DE COMPETENCIAS}

En la primera mitad de la década de los ochenta, concretamente en 1984, se produce el traspaso de competencias, que en el caso emeritense se traduce en el hecho de que sólo se reformó parcialmente el Patronato de la Ciudad Histórico-Artística y Arqueológica. El mencionado cambio no consistió en potenciar la política emprendida, ya que no se incrementó el personal, ni los medios. Sin embargo, el Patronato se responsabilizó de la salvaguarda del Patrimonio Arqueológico de toda Extremadura. Es evidente que ante lo exiguo de los medios, la situación empeoró claramente, pues se continuó con el seguimiento de obras en el casco urbano emeritense, y sin embargo la plantilla de arqueólogos no aumentó, lo que provocó que los resultados de todas las excavaciones de estos años no llegaran a ver la luz, aunque, se conoce su realización gracias a la mención que de ellas se hace en la serie Arqueología del Ministerio de Cultura.

En 1985 se aprobó la Ley de Patrimonio Histórico Español, lo que abría nuevas perspectivas a la Arqueología española en general, y a la urbana en particular. Se sientan las bases para que se cumplan los nuevos objetivos que deben redundar en concebir la ciudad como un yacimiento único $y$, por tanto, debe existir un Proyecto Integral de Arqueología Urbana. Este aspecto ha sido ampliamente tratado por Fernández Ochoa y Querol (2000). Según estas autoras, el Proyecto Integral engloba cuatro aspectos indispensables: investigación, restauración, integración y difusión. Para conseguir esto, es condición si ne qua non que el sistema de registro esté unificado, tanto en excavación como para el estudio de los materiales. Esto se puede lograr no sólo mediante el establecimiento de un criterio unificado, sino también con la coordinación única de los trabajos en la ciudad, aunque para ello no sea imprescindible que se trate de un cargo unipersonal, ya que lo puede asumir un equipo. Asimismo, es conveniente que exista una estrecha colaboración entre Arqueología y Urbanismo, o lo que es lo mismo, entre el coor-

12 Es la que conocemos como Casa del Anfiteatro, parcialmente excavada por García Sandoval. Álvarez Martínez, años más tarde, excava el ala más próxima al desarenador del acueducto de San Lázaro, de ahí esa denominación. En el proceso se sacó a la luz la arcuatio que dicha conducción hidráulica posee en este sector. La memoria de la excavación está en curso. (Sánchez Sánchez y Nodar Becerra, 1997, 378 y 379)

13 Memoria en proceso de elaboración. 
dinador del área de Intervención Arqueológica de la ciudad y la Gerencia de Urbanismo de los Ayuntamientos. Es altamente recomendable la comunicación y participación activa entre la Universidad y los responsables, ya sean personas o empresas, que puedan emprender estos trabajos. El último escalón de todos estos esfuerzos lo constituye la difusión, estructurada en tres niveles: científica, divulgativo-pedagógica y patrimonial, cuyo colofón debe traducirse en programas de turismo cultural (Fernández Ochoa y Durán Cabello, 2006, e. p.).

No es hasta 1987 cuando se aprecia un cambio substancial en las normativas urbanísticas emeritenses. Estos es debido al hecho de que Mérida asume, ese año, la capitalidad de la autonomía extremeña. Esto supuso un impulso para la modernización de la ciudad, y se dejó sentir de manera especial en el terreno urbanístico e inmobiliario, habida cuenta de la necesidad de crear nuevos edificios para albergar las diferentes Consejerías. Dicha situación condujo a la redacción de un nuevo Plan General de Ordenación Urbana (PGOU) (Fernández Ochoa y Durán Cabello, 2006, 114, $\mathrm{n}^{\circ} 1$ ), que en sí mismo era un notable avance, aunque presentaba importantes carencias. En principio, el Patronato deja de estar bajo autoridad del Consistorio para pasar a depender de la Consejería de Cultura. Al frente de la Dirección de Patrimonio se nombró un arqueólogo, D. Juan Javier Enríquez Navascués, que debía realizar un seguimiento de todas las licencias de obras que concedía el Ayuntamiento, además de supervisar todo el territorio extremeño. Estuvo auxiliado por los arqueólogos D. Manuel Alvarado González y Dña. Eulalia Gijón Gabriel. El personal y los medios económicos eran más que insuficientes. Como consecuencia de esta situación, las memorias han ido viendo la luz lentamente (Enríquez Navascués, 1994-95; Enríquez Navascués et alii, 1991). Hay que señalar que ha habido avances mediante noticias publicadas ${ }^{14}$ en el anuario del Ministerio de Cultura, Arqueología, correspondiente al bienio 1984-85.

Entre las zonas excavadas destacan: la denominada necrópolis oriental (zona teatro-anfiteatro), donde se hallaron mausoleos y tumbas de incineración; la denominada como necrópolis

14 Respecto a las publicaciones, debemos subrayar que a partir del año 1988 nace la revista Extremadura Arqueológica, patrocinada por la Junta de Extremadura. No va a tener una periodicidad concreta, manteniendo en los últimos años una salida irregular. En un principio trata de recopilar las intervenciones realizadas en la Comunidad Extremeña, para pasar posteriormente a del "Disco", en cuyas inmediaciones se localizaron vestigios de una construcción agraria; igualmente se exhumaron restos domésticos de época romana, así como otros de carácter industria ${ }^{15}$ en la c/ Almendralejo y en la Alcazaba.

\section{Merida, Patrimonio de la HUMANIDAD}

Un hecho que influyó de manera notable en la vida de Mérida fue la concesión del título de Ciudad Patrimonio de la Humanidad, galardón que consiguió el 8 de diciembre de 1993. Supuso, en general, un acicate para la Junta de Extremadura y, en particular, para la Consejería de Cultura, que se tradujo en la creación de un nuevo Patronato, germen de un organismo posterior más específico.

En efecto, tres años después, en 1996, la arqueología emeritense se beneficia del nacimiento del Consorcio de la Ciudad Monumental Histórico-Artística y Arqueológica de Mérida. En él participan el Ministerio de Cultura, la Consejería de Cultura de la Junta de Extremadura, la Diputación Provincial de Badajoz y el Ayuntamiento de Mérida. Entre sus objetivos estaba el compromiso de conservar, mantener y revalorizar el conjunto monumental de la ciudad, así como el estudio de los restos y su valoración para integrarlos en la ciudad. El Consorcio parte de la premisa según la cual, la peculiaridad de Mérida radica en ser un yacimiento unitario, de carácter global; por tanto, la Arqueología Urbana debe regirse por criterios estrictamente unificados, lo que redunda en el avance sobre el conocimiento de la evolución y singularidad de las ciudades superpuestas (Lozano Bartolozzi, 2000, 132). La gestión del Consorcio se vio reforzada merced a la Ley de Patrimonio Histórico y Cultural de Extremadura, promulgada en 1999.

$\mathrm{Al}$ frente del Consorcio estaban Dña. $\mathrm{M}^{\mathrm{a}}$ del Mar Lozano, Directora General, y D. José $\mathrm{M}^{\mathrm{a}}$ Soriano Llamazares, Gerente. Como responsable de la coordinación arqueológica se nombró a D. Pedro Mateos Cruz, y como arqueólogos a Dña. Juana Márquez, D. Miguel Alba, D. Félix Palma, D. José Carlos Saquete, Dña. Ana Bejarano y Dña. Teresa Barrientos, ente otros. Este equipo,

dedicar algunos números a temas monográficos.

15 Conviene señalar que existen publicaciones de carácter general, especialmente relativas a las áreas funerarias, aunque también recogen otros aspectos. Vide Enríquez y Gijón, 1987; Alvarado et alii, 1995; Molano et alii, 1991 y 1995. En general, para una información más precisa, Velázquez Jiménez, 2002. 
se ha mantenido en lo básico aunque con el paso del tiempo se ha ido incrementando.

Metodológicamente se instaura un sistema de excavación y documentación unificado. Para el proceso de excavación se sigue el método de registro Harris, mientras que en el apartado de la documentación se recogen diversos aspectos: el informe arqueológico, la documentación fotográfica y planimétrica, la ficha de la zona arqueológica excavada en la que figura la hoja del parcelario, la manzana y el solar en el que se interviene, el uso de las estructuras aparecidas, la cronología de las mismas, y su posible relación con otras ya contrastadas, y geográficamente próximas. Todos estos datos son incluidos con posterioridad, en planos arqueo-cronológicos realizados a escala 1/1000 y 1/5000 (Mateos Cruz, 1997, 217), de manera que la información siempre puede ser hallada y consultada rápidamente $\mathrm{y}$, en su caso, completada si se acometiesen nuevas intervenciones.

A principios de los años noventa, destacan dos grandes excavaciones tanto por la superficie excavada como por la importancia de los restos hallados. Nos referimos a las excavaciones practicadas en el interior de la iglesia de Santa Eulalia -1990-1992- (Caballero Zoreda y Mateos Cruz, 1993; 1993b, 15-50) y la intervención en la denominada Área Arqueológica de Morería, que se realizó entre 1990 y 1998 (Alba Calzado, 1997; Alba Calzado y Navareño Mateos, 1997). En ambos casos se van cumpliendo los objetivos propugnados por el Consorcio: excavación, estudio, publicación, conservación y puesta en valor, sin olvidar la divulgación ${ }^{16}$.

En el caso de Santa Eulalia, además de alcanzar los objetivos de conservación y puesta en valor, así como de su publicación -tanto científica como divulgativa-, se acometió la musealización de los restos mediante la creación una cripta arqueológica y un centro de interpretación anexo. En este yacimiento se puede contemplar la evolución del lugar desde el s. I d.C., hasta el siglo XIX. Del primer momento datan unas estructuras domésticas atribuidas a cuatro domus superpuestas. Con el levantamiento del tumulus de la Santa sobre las ruinas anteriores en el s. IV d.C., y hasta el siglo VI d.C., el lugar pasó a convertirse en una importante área funeraria cristiana. Es en el siglo XIII cuando se construye la

16 La difusión se estructura en tres publicaciones. La primera, de carácter eminentemente especializado, Memoria. Mérida, Excavaciones Arqueológicas, desde 1994, en la que se recopilan informes de excavación y artículos. La segunda, también especializada, Mérida. Ciudad y
Iglesia actual. Edificio que ha sufrido a lo largo de estos años múltiples reformas. (Caballero Zoreda y Mateos Cruz, 1993 y 1993b).

La excavación del Área Arqueológica de Morería está permitiendo documentar un amplio periodo crono-cultural: desde restos asignables al Paleolítico inferior, que podrían indicar un posible uso como cazadero, pasando por una fase calcolítica, otra más importante y "estable" perteneciente al tránsito del Bronce final al Hierro, las primeras construcciones de la primera época de la colonia, su continuidad en el periodo tardorromano, hasta su transformación durante la fase emiral y cambio de uso en época taifa (maqbara). El solar, nuevamente amortizado, volvió a ser ocupado desde el s. XIII, tras la conquista de la ciudad por la Orden de Santiago, hasta nuestros días (Mosquera, 1994; Alba, 1997). Los restos han sido integrados entre las cimentaciones de los edificios que albergan diversas consejerías. Creemos que se trata de una más que discutible intervención urbanística respecto a la realidad arqueológica emergente, sobre la que existen opiniones encontradas: unas a favor (Alba y Navareño, 1997, 55-56) y otras en contra (Rodríguez Temiño, 2004, 111). Como en el caso de la iglesia de Santa Eulalia, aquí también se ha abierto recientemente un centro de interpretación que integran el yacimiento en el conjunto de monumentos visitables de la ciudad.

Se han realizado en estas fechas infinidad de intervenciones en la ciudad, ya que es preceptivo realizar sondeos arqueológicos ante de comenzar una obra. Con el objetivo de recoger y dar a conocer el resultado de todas las intervenciones arqueológicas que se realizan en Mérida, tanto de signo negativo como positivo, nace en 1994 la publicación Memoria. Mérida, Excavaciones Arqueológicas. En ella se recogen estudios puntuales relacionados con las excavaciones arqueológicas realizadas, aportando, además, una visión muy completa del panorama de la actividad arqueológica.

Entre el gran número de intervenciones llevadas a cabo en la ciudad, en estos últimos años, queremos señalar por la importancia de los datos aportados: la realizada junto al pórtico del teatro (Mateos y Márquez, 1997), las del Alcazaba (Feijoo, 1999), las de la calle Espronceda -con importantes restos de un mitreo-(Barrientos,

Patrimonio, encaminada a dar a conocer los proyectos relativos al patrimonio urbano. Y la tercera de ellas, de carácter didáctico, es el boletín Foro, donde se transmite al gran público lo esencial de los hallazgos y noticias acaecidas durante el trimestre. 
2001), las realizadas en las distintas necrópolis -tanto hispanorromanas (Márquez, 1997 y 2002; Bejarano, 1999), como musulmanas (Sánchez, 1999)-, o las efectuadas en distintos puntos de la ciudad que han conducido a un mejor conocimiento del viario romano (Palma, 1999; Alba, 2000 y 2002).

En los últimos años, el Consorcio de la Ciudad Monumental de Mérida no solo se ha limitado a cumplir con las metas enumeradas con anterioridad, sino que, en una labor cada vez más exigente, ha abordado diversos proyectos de investigación -algunos de ellos, como Morería, iniciados con anterioridad-, en unos casos actuando directamente, y en otros dando su apoyo; como ocurre, por ejemplo, con el Proyecto de Investigación "Zona Arqueológica del Circo" (ZAC). Dicho proyecto nace en 1987 como consecuencia de un acuerdo subscrito entre el Ayuntamiento de Mérida y la Consejería de Cultura de la Junta de Extremadura. En él se decide desviar la antigua carretera MadridLisboa, que dividía en dos el recinto arqueológico. Los primeros sondeos se acometen en 1989, prolongándose los trabajos, de manera intermitente, hasta 1993-94. Durante este periodo las intervenciones son dirigidas por D. Javier Sánchez-Palencia, Dña. Ana $\mathrm{M}^{\mathrm{a}}$ Montalvo Frías y Dña. Ma Eulalia Gijón Gabriel. Finalizada esta primera fase, se acomete un segundo proyecto encaminado a excavar y documentar exhaustivamente el circo. Se pretende, además de su estudio, poner en valor dicha zona arqueológica e integrarla dentro del tejido urbano, potenciando tanto su rentabilidad social como su comprensión histórico-cultural (Sánchez-Palencia et alii, 2001, 78). Posteriormente, ha sido englobado dentro de un Proyecto mucho más ambicioso: "Alba Plata".

El Proyecto "Alba Plata" fue aprobado en el mes de julio de 1997. Está financiado por el Banco Europeo a través de los fondos FEDER, correspondiendo la administración a la Junta de Extremadura, más concretamente a la Consejería de Cultura. Entre sus objetivos se encuentra la recuperación de la calzada de la ruta de la Plata, restaurando o reintegrando los tramos mejor conservados de la misma, y señalizando su recorrido. También se contemplan treinta intervenciones en conjuntos monumentales, edificios públicos, civiles y religiosos, así como actuaciones en arquitectura popular, obras públicas y espacios naturales. Mérida canalizó dichos aportes en tres direcciones: el acueducto de Los Milagros, en el que se realiza un estudio arqueológico y petrológico, y se contempla la restauración de los tramos más afectados; la cabecera del puente sobre el Guadiana, donde se está instalando un Centro de Interpretación sobre el discurrir de la ciudad a lo largo de la historia; y el Circo romano, que se habilitó para ser visitado como zona arqueológica y en cuyas inmediaciones se rehabilitó una casa tradicional para albergar un Centro de Interpretación sobre el Urbanismo de la Mérida romana, inaugurado en enero de 2003.

Entre 1999 y 2001, el Consorcio puso en marcha un Proyecto de Investigación sobre el "Foro Provincial de Augusta Emerita". Está aprobado por la Consejería de Educación dentro del primer programa I+D de la Junta de Extremadura. En la actualidad está en fase de ejecución. En el se contempla, además, el estudio del conocido como "Arco de Trajano" (Mateos Cruz, 1999, 2).

Otro Proyecto de Investigación acometido por el Consorcio ha sido el del "Área Funeraria de los Columbarios". En este proyecto, iniciado en 1998, se aunaron varios objetivos como eran la reexcavación de los llamados Columbarios, la consolidación y restauración de los mismos, así como de sus famosas pinturas, y la realización de un Centro de Interpretación del mundo funerario en época romana. En este proyecto participaron, además del Consorcio, el Servicio de Obras y Proyectos de la Consejería de Cultura, y personal del área de Restauración del Museo Nacional de Arte Romano. Se ha puesto en funcionamiento en 2003 (Lozano, 2003).

En Septiembre del año 2000 se funda el Instituto de Arqueología de Mérida (IAM), como Centro de investigación de titularidad mixta: Consejo Superior de Investigaciones Científicas (CSIC), la Junta de Extremadura y el Consorcio de la Ciudad Monumental de Mérida. Tiene como principal objetivo fomentar la investigación arqueológica en toda la Comunidad Autónoma Extremeña, desarrollando, además, proyectos de carácter nacional e internacional. Las líneas de investigación se centran en la Protohistoria, el mundo Hispanorromano y la Tardoantigüedad. Dentro de estos ámbitos, las pautas de estudio se enfocan hacia la Arqueología de la Arquitectura y el estudio del territorio aplicando ensayos geofísicos.

El Museo Nacional de Arte Romano, durante estos años ha centrado su labor en el campo de la difusión y la investigación. Dentro de la institución se han llevado a cabo numerosas exposiciones temporales, como por ejemplo "Hispania. El Legado de Roma" (1999), "Aquae Aeternae" (2000), "Mérida y la arqueología ilustrada" (2001), o "Ludi Romani" (2002), etc., así como un buen número de encuentros científicos -tanto nacionales como internacionales-, ciclos de conferencias, mesas redondas, etc. Como órgano de 
difusión cuenta con una revista, Anas, y dos publicaciones dedicadas a temas monográficos: Monografías Emeritenses y Cuadernos Emeritenses, con 8 y 26 volúmenes publicados, respectivamente.

En 1996 se crea la Fundación de Estudios Romanos, con la finalidad de fomentar, ayudar y apoyar todo tipo de actividades científicas, artísticas y culturales relacionadas con el legado romano. A través de este organismo se están llevando a cabo proyectos de Investigación y Desarrollo Tecnológico $(\mathrm{I}+\mathrm{D})$, sobre Mérida romana como: Augusta Emerita: Territorio, Espacios, Imágenes y Gentes en la Lusitania Romana.

\section{A Modo de Conclusión}

Como se puede deducir de la lectura de estas páginas, la renovación experimentada por la Arqueología emeritense en los últimos 25 años ha sido espectacular. Uno de los avances más importantes ha sido pasar a considerar la ciudad de Mérida como un yacimiento único con una amplia secuencia cultural y cronológica. Fruto de esta conclusión ha sido aplicar el postulado de que si se trata de un yacimiento unitario, tanto el método de excavación, como el de documentación, restauración, difusión y puesta en valor, deben atenerse a unos criterios claros y unitarios; de manera que independientemente de los arqueólogos que excaven, el sistema siempre será el mismo. Esta situación que contrasta netamente con los periodos anteriores, donde no se tenía el concepto de yacimiento unitario, ni el sistema de excavación empleado era el mismo (Wheeler-Lamboglia) (Fernández- Ochoa y Durán Cabello, 2006, 128)

Entre 1985 y 1993, el concepto de "ciudad = yacimiento único" ya está presente, pero aún no se ha articulado el protocolo de actuación arqueológica. Se trata claramente de una etapa de transición, con todas sus virtudes -ya que se concibe a Mérida como una unidad arqueológica con múltiples fases ocupacionales-, e inconvenientes -entre los que destaca la escasa difusión de los resultados-. Metodológicamente conviven los dos sistemas de excavación: el Wheeler-Lamboglia y el método Harris, este últi-

17 Para etapas correspondientes a la Prehistoria y Protohistoria emeritenses, véase la recopilación bibliográfica de Velázquez Jiménez (2002).

18 Este interés se refleja tanto en las excavaciones practicadas recientemente (Mateos Cruz y Márquez Pérez, 1997), como en los proyectos de investigación acometidos (Sánchez Palencia, Montalvo y Gijón, 2001), así mo ganando cada vez más terreno al anterior.

Por último, el periodo que va desde 1994 hasta el 2000, en el que se ha establecido plenamente el protocolo de intervención arqueológica: el sistema de excavación se ha unificado en torno al método Harris; la documentación es exhaustiva y fácilmente accesible; y la difusión de los avances en el conocimiento de las diversas "méridas" es impecable, tanto desde la perspectiva científico-arqueológica, como en la científicopatrimonial, sin olvidar la vertiente didáctica. A este último aspecto se le ha dedicado una especial atención, lo que se ha traducido en la creación de varios centros de interpretación, cuyo resultado ha sido integrar las estructuras arqueológicas exhumadas dentro de la trama urbana, para cumplir con su función social y educadora, y cuyo último objetivo no es otro que la concienciación ciudadana en pro del respeto por aquello que es suyo, su propio pasado, su Historia.

A la vista de todo lo expuesto, debemos hacernos la siguiente pregunta: ¿qué sabemos de la ciudad de Mérida a través de la Arqueología Urbana, más allá de las hipótesis clásicas?. Esta pregunta posee una respuesta que puede ser estructurada en varios niveles.

En primer lugar, es evidente que el mayor nivel de información que poseemos es relativo a la Mérida hispanorromana ${ }^{17}$. Dentro de este apartado, tenemos que puntualizar que el conocimiento de las diversas facetas de la cultura hispanorromana es desigual. Así, en lo que se refiere a arquitectura, observamos que los edificios de espectáculo -teatro, anfiteatro y circo- siguen acaparando la mayor atención, siguiendo una tendencia propia de la Arqueología Clásica, que afortunadamente va siendo superada en los trabajos más recientes sobre dichos monumentos ${ }^{18}$. Sin embargo, pese a conocer ahora, de manera más precisa, cómo y cuando se construyeron teatro, anfiteatro y circo, carecemos todavía de una secuencia cronoestratigráfica completa, que nos informe desde los primeros momentos de ocupación de estos solares hasta el presente ${ }^{19}$.

Del resto de edificios públicos visibles en la actualidad, el volumen de conocimiento disminuye de manera notable. Aunque ya hace varias

como en trabajos de investigación (Durán Cabello, 1998b y 2004) y difusión (Nogales Basarrate, 2000).

19 Existen cronoestratigrafías, tanto del circo como del teatro, pero ninguna de ellas puede atestiguar la secuencia completa de las distintas fases históricas hasta nuestros días. 
décadas se percibía la existencia de dos áreas forales en la ciudad (foro provincial y colonial), nuestra información sobre los mismos todavía es sorprendentemente limitada, y está centrada más en los aspectos decorativos que en los urbanísticos, aunque en los últimos años se están haciendo importantes avances. Recientemente ha visto la luz la primera monografía sobre estos ámbitos, centrada en el llamado templo de Diana. (Álvarez Martínez y Nogales Basarrate, 2003). En ella se aborda un estudio formal del mismo y se propone su posible imbricación dentro de la trama urbana $^{20}$.

Respecto a los avances conseguidos dentro del conocimiento urbanístico debemos decir, rotundamente, que se ha incrementado notablemente la información relativa al recinto urbano emeritense aunque de manera desigual, como se verá seguidamente.

Por lo que se refiere a los acueductos, a pesar de que se han realizado levantamientos topográficos de alguno de ellos, como el caso de Rabo de Buey (Hernández Ramírez et alii, 1996; Hernández Ramírez, 1998), y se encuentran en proceso de elaboración estudios arqueológicos integrales, apenas hemos conocido datos nuevos respecto a lo publicado desde finales de los años setenta. Algo semejante podemos decir sobre los puentes romanos de la ciudad, para cuyo conocimiento sigue siendo básico el trabajo de Álvarez Martínez (1983) aunque recientemente han aparecido trabajos muy meritorios, que acometen el estudio del puente con una metodología propia de la Arqueología de la Arquitectura (Feijoo, 1997) o, el de uno de nosotros, en el que se aborda la investigación del mismo monumento desde la perspectiva de la Arqueología del Paisaje (Rodríguez Martín, 2004, e. p.).

Una de las cuestiones más desconocidas de la arquitectura emeritense es el trazado y cronología de la muralla de la ciudad. Dejando al margen las premisas clásicas sobre el papel de la muralla en la fundación colonial (Calero, 1986 y 1992), que han arrojado mucha confusión sobre este aspecto, tan sólo en la última década hemos conocido algunos datos arqueológicos reales sobre la obra defensiva, gracias fundamentalmente a los trabajos desarrollados en Moreria (Alba, 1997; Mosquera Müller, 1994). El recinto amurallado originario parece haber sufrido diversas modificaciones estructurales entre los siglos I y V d. C.

La preferencia de los investigadores hacia los edificios romanos más monumentales ha determinando que nuestra información sobre la arquitectura doméstica haya sido muy limitada ${ }^{21}$ hasta la renovación metodológica experimentada por la arqueología hispanorromana a partir de mediados de los años ochenta del siglo XX (Fernández Ochoa \& Durán, 2006, 130.). En los últimos años se han venido obteniendo nuevos datos gracias a las intervenciones practicadas en ámbitos domésticos (Palma García, 1997; Sánchez Sánchez y Nodal Becerra, 1997), que nos ofrecen un panorama cada vez más completo sobre las domus emeritenses, aunque, siguiendo una tendencia muy marcada en la arqueología hispanorromana en su conjunto, la vivienda popular sigue siendo la gran desconocida.

Semejante al progreso experimentado por la arquitectura doméstica, en lo que a conocimiento se refiere, ha sido el avance relativo a las áreas de necrópolis, especialmente desde la celebración del coloquio conmemorativo del bimilenario (Bendala, 1976). Son múltiples las excavaciones que han dado a conocer las distintas áreas de enterramiento en la ciudad ${ }^{22}$.

En los últimos veinte años se ha dado un salto cualitativo en el estudio de materiales. También en este caso el progreso, claramente impulsado desde el MNAR, se ha centrado más en los restos decorativos, tanto escultóricos como arquitectónicos, así como en epigrafía y numismática ${ }^{23}$. Por el contrario, el avance ha sido mucho más limitado en el conocimiento de otro tipo de materiales,
20 Recientemente se está llevando a cabo un proyecto de investigación "Documentación e integración urbanística y desarrollo turístico del templo de Diana y su entorno", que imbrica con otro, "Proyecto integral del foro municipal de la colonia romana". Al amparo de estas actuaciones se han realizado excavaciones que han permitido obtener la secuencia cronoestratigráfica completa del sector oriental del temenos (Palma, 2003: 427445 .

21 Sobre todo hasta la fecha de 1975. Sin embargo, hay excepciones como por ejemplo la "Casa del Anfiteatro" o la "Casa del Mitreo". En las publicaciones de ambas estructuras, se aprecia que la atención se centraba en aspectos decorativos como mosaicos y hallazgos de escultura, pintura etc. A partir de la fecha arriba men- cionada y gracias a los trabajos del profesor Balil, se asiste a una renovación en este ámbito del conocimiento de la arqueología hispanorromana en general, y emeritense en particular (1976).

$22 \mathrm{El}$ conocimiento de necrópolis y las áreas periurbanas en su conjunto, es el capítulo donde el progreso del conocimiento ha sido más acusado. Ver la revista Memoria. Mérida, Excavaciones Arqueológicas y Velázquez Jiménez, 2002)

23 En este sentido, consúltese las series del MNAR, Monografías Emeritenses y, especialmente, Cuadernos Emeritenses. 
como cerámica, bronce o vidrio. En este sentido, se han dado a conocer monografías y artículos sobre sigillata, lucernas, vidrio, monedas, etc. Pero en la mayoría de los casos, se han estudiado desde un punto de vista tipológico o decorativo, casi siempre descontextualizados y sin referencias estratigráficas.

Este hecho nos pone ante una de las grandes carencias de la arqueología emeritense en la actualidad: la escasez de publicaciones donde se aborde un estudio cronoestratigráfico completo de los restos arqueológicos, tanto arquitectónicos como de los contextos materiales. A pesar de los meritorios intentos para corregir esta tendencia por parte del Consorcio y de algunos investigadores aislados, esta descontextualización influye muy negativamente en el conocimiento de la configuración urbanística y del desarrollo histórico de la colonia Augusta Emerita. Sin ir más lejos, este hecho impide conocer en profundidad, desde un punto de vista arqueológico, el proceso de fundación y los primeros compases de la vida de la ciudad.

\section{Bibliográfia}

ALBA CALZADO, M. (1997): “Ocupación diacrónica en el área arqueológica de Morería (Mérida)", Memoria 1, Mérida, Excavaciones Arqueológicas, 199495, pp. 285-315.

(1998): “Consideraciones arqueológicas en torno al siglo V en Mérida: Repercusiones en las viviendas y en la muralla" Memoria 2, Mérida. Excavaciones Arqueologicas, 1996, pp. 361-385.

(2000): "Intervención arqueológica en el solar de la C/Suárez Somonte, esquina con C/Sáenz de Buruaga: Transición de un espacio doméstico y viario de época romana a la tardo antigüedad", Memoria 4, Mérida, Excavaciones Arqueológicas, 1998, pp. 277-303

(2001): "Mérida, entre la tardoantigüedad y el Islám: datos documentados en el área Arqueológica de Moreria", La islamización de la Extremadura romana [Valdés, F. y Velázquez, A., eds. Cuadernos Emeritenses, 17] Mérida, pp. 267-308.

(2001): "Características del viario urbano de Emerita entre los siglos I y VIII", Memoria 5, Mérida, Excavaciones Arqueológicas, 1999, pp. 397- 423.

(2002): "Datos para la reconstrucción diacrónica del paisaje urbano de Emerita: Las calles porticadas desde la etapa romana a la visigoda", Memoria 6, Mérida, Excavaciones Arqueológicas, 2000, pp. 371396.
ALBA CALZADO, M. y NAVAREÑO MATEOS, A.(1997): "Morería (Mérida): 2000 años de actividad constructiva", Vivir las ciudades históricas. Ciudades modernas superpuestas a las antiguas. 10 años de investigación, pp. 55-69.

ALVARADO GONZALO, M.; MOLANO BRÍAS, J. y GIJÓN GABRIEL, E. (1995): "Excavaciones de urgencia en la c/ Almendralejo 58-60 (Mérida)", XXI C.A.N., III, Zaragoza, pp. 995-1010.

ÁLVAREZ MARTÍNEZ, J. M. (1973): "Excavaciones arqueológicas en el Templo de Diana”, Bellas Artes $73, \mathrm{n}^{\mathrm{o}} 21$, p. 42.

(1973b): "Excavaciones arqueológicas en el Templo de Diana”, Bellas Artes 73, n 27, pp.60-61.

(1976): "El templo de Diana”, Augusta Emerita, Madrid, pp.43-54.

(1977): "En torno al acueducto de 'Los Milagros' de Mérida”, Segovia y la Arqueología Romana, Madrid, pp.49-60.

(1977b): "Informe sobre las excavaciones realizadas en el Templo de Diana (Mérida)”, NAH-Arqueología, 5, Madrid, pp. 89-96.

(1982): "El foro de Augusta Emerita”, Homenaje a Sáenz de Buruaga, Badajoz, pp.53-68.

(1983): El puente romano de Mérida [Monografías Emeritenses, 1], Badajoz.

(1985): "Excavaciones en Augusta Emerita", Arqueología de las ciudades modernas superpuestas a las antiguas (Zaragoza, 1983), Madrid, pp. 37-53.

(1991): "El templo de Diana", Templos Romanos de Hispania, Cuadernos de Arquitectura Romana, I, pp. 83-93.

(1996): "Semblanza de Eugenio García Sandoval", El Mosaico cosmológico de Mérida. Eugenio García Sandoval. In Memoriam, Cuadernos Emeritenses, 12. Mérida.

ÁLVAREZ MARTÍNEZ, J.M. y NOGALES BASARRATE, T. (1990): "Schema urbain en Augusta Emerita. Le portique de Forum", Akten des XIII Internationalen Kongresses för Klassische Archäologie, Berlín, pp. 336338.

(2003):Forum coloniae Augustae Emeritae. Templo de Diana, Mérida.

ÁLVAREZ SÁENZ DE BURUAGA, J. (1950): "Las ruinas de Emerita y de Itálica a través de Nebrija y Rodrigo Caro", REE (tirada aparte).

(1958): "Mérida y los viajeros", REE, Badajoz, 561 ss. 
(1974): "Una casa romana, con valiosas pinturas, de Mérida”, Habis, 5, pp. 169-187.

(1982): "Observaciones sobre el teatro romano de Mérida”, Actas del Simposio El teatro en la Hispania romana, Badajoz, pp. 303-311.

ÁLVAREZ SÁENZ DE BURUAGA, J. y ÁlVAREZ MARTÍNEZ, J. Ma . (1977): "Informe sobre los trabajos realizados en el Circo Romano de Mérida”, NAH-Arqueología, 5, pp. 100-103.

AUGUSTA EMERITA (1976), Actas del Coloquio en conmemoración del Bimilenario de la fundación de Mérida (1975). Mérida.

BALIL ILLANA, A. (1976): "Sobre la arquitectura doméstica en Emérita”, Augusta Emerita, pp. 75-92.

BARRERA ANTÓN, J. L. de la (2000): La decoración arquitectónica de los foros de Augusta Emerita, Roma.

BARRIENTOS VERA, T (2001): "Nuevos datos para el estudio de las religiones orientales en Occidente: un espacio de culto mitraico en la zona Sur de Mérida", Memoria 6, Mérida, Excavaciones Arqueológicas, 2000, pp. 357-381.

BEJARANO OSORIO, A. Ma (1999): "Nuevas interpretaciones en el espacio funerario conocido como 'necrópolis oriental' de Mérida", Memoria 5, Mérida, Excavaciones Arqueológicas, 1999, pp. 243253

BENDALA GALÁN, M.(1976): "Las necrópolis de Mérida", Augusta Emerita, pp. 141-162.

BENDALA GALÁN, M. y DURÁN CABELLO, R. M. (1995): "El anfiteatro de Augusta Emerita: rasgos arquitectónicos y problemática urbanística y cronológica", El Anfiteatro en la Hispania Romana (Mérida, 1992), Badajoz, 265 ss.

CABALLERO ZOREDA, 1. Y MATEOS CRUZ, P. (1993): Santa Eulalia de Mérida. Excavación Arqueológica y Centro de Interpretación. Patrimonio Histórico de Extremadura. Guías Arqueológicas-3. Mérida.

(1993b): "Trabajos arqueológicos realizados en la iglesia de Santa Eulalia de Mérida", Jornadas sobre Santa Eulalia de Mérida, Extremadura Arqueológica, III, Mérida, pp. 15-50.

CALERO CARRETERO, J. A. (1986): La muralla romana de Augusta Emerita, Memoria de Licenciatura, inédita.

(1992): "La muralla romana de Augusta Emerita: apuntes para una bibliografía crítica de los estudios sobre el recinto", REE, LVIII, pp. 259-275.

CALDERA DE CASTRO, Ma.P. (1983): "El vidrio romano emeritense”, Emerita Augusta I.E.A.E. $n^{0}$ 126, pp.1-81.
DURÁN CABELLO, R. M. (1998): Estudio arquitectónico del teatro y del anfiteatro de Augusta Emerita: nuevas bases arqueológicas para la historia de la ciudad. Servicio de Publicaciones de la Universidad autónoma de Madrid. Tesis microfichada. ISBN: 84-7477-695-3

(1998b): La última etapa del teatro romano de Mérida. La uersura oriental y los sellos latericios. Cuadernos Emeritenses, 14. Mérida.

(2004): El teatro y el anfiteatro de Augusta Emerita. Contribución al conocimiento histórico de la capital de Lusitania, BAR International Series, 1207. Oxford.

ENRÍQUEZ NAVASCUÉS, J. J. y GIJÓN GABRIEL, E. (1987): Arqueología Urbana en Mérida. La necrópolis del Albarregas. Mérida.

ENRÍQUEZ NAVASCUÉS, J. J. et al. (1991): "Excavaciones arqueológicas en Mérida (19861990)", Extremadura Arqueológica II (1 ${ }^{a}$ Jornadas de Prehistoria y Arqueología), pp.599-609.

ENRÍQUEZ NAVASCUÉS, J. J. (1995): "Relación de sondeos y excavaciones arqueológicas llevadas a cabo en Mérida entre 1987 y 1991", Anas 7-8/, 19941995, pp.143-158.

FEIJOO MARTÍNEZ, S. (1997): "Aspectos constructivos del Puente Romano de Mérida”, Memoria 3, Mérida, Excavaciones Arqueológicas, 1997, pp.321-337.

(2001): "El aljibe de la alcazaba de Mérida. $1^{\mathrm{a}}$ campaña de intervención arqueológica en la zona norte y oeste del aljibe", Memoria 5, Mérida, Excavaciones Arqueológicas, 1999, pp. 191-212.

FERNÁNDEZ OCHOA, C. y DURÁN CABELLO, R. M. (2005): "García y Bellido y la Arqueología urbana hispanorromana. De los sondeos a la planificación integral”, La Arqueología Clásica Peninsular. En el centenario de Antonio García y Bellido, Madrid, e.p.

FERNÁNDEZ OCHOA, C. y QUEROL, M. A. (2000): "Arqueología Urbana en España", III Congreso Peninsular de Arqueología, vol. VIII, Porto, pp.11-20.

FLORIANO CUMBREÑO, A. (1940/41): "Las excavaciones de Mérida", AEspA, 14-15, 445 ss.

GARCÍA MERCADAL, J (1952): Viajes de extranjeros por España y Portugal, Madrid.

GARCÍA SANDOVAL, E. (1966): Informe sobre las casas romanas de Mérida y excavaciones en la "Casa del Anfiteatro". EAE, 49.

(1969): La casa romana del Anfiteatro. Mérida.

(1969b): "El mosaico cosmogónico de Mérida", BSEAA, XXXIV-XXXV, pp. 9-29. 
HERNÁNDEZ RAMÍREZ, J.; CANITO LOBO, J. y CARRASCO CELEDONIO, V. (1996): "Un ejemplo de la ingeniería hidráulica romana: el conducto de Rabo de Buey-San Lázaro (Mérida)", VIII Congreso Internacional de Ingeniería Gráfica, Jaén, pp. 417-449.

HERNÁNDEZ RAMÍREZ, J. (1998): "El conducto de Rabo de Buey-San Lázaro (Mérida)", Mérida. Ciudad y Patrimonio 2, pp. 39-66.

JEREZ LÍNDE, J. M (1996): “Valerius Paternus. Notas para la clasificación tipológica de las marcas alfareras procedentes de la cuenca media del Guadiana”, Mélanges de la Casa de Velázquez, XXXII, pp. 113138.

LEQUEMENT, R. (1978): "Rapport préliminaire sur deux sondages effectués à Mérida. Septiembre-octubre 1973", NAH-Arqueología, 5, pp. 145-166.

LOZANO BARTOLOZZI, M". M. (2000): "Arqueología y musealización en el yacimiento de Mérida", I Congreso Internacional Ciudad, Arqueología y Desarrollo. La Musealización de los yacimientos arqueológicos, Alcalá de Henares, pp. 131-137.

(2003): "El centro de interpretación en el área funeraria de Los Columbarios, espacio de paseo, conocimiento y reflexión", Foro, 32, Mérida, pp. 2-5.

MARCOS POUS, A. (1961): "Dos tumbas emeritenses de incineración”, AEspA, pp. 34-90 ss.

MÁRQUEZ PÉREZ, J. (1998): "Nuevos datos sobre la dispersión de las áreas funerarias de Emerita Augusta”, Memoria 2, Mérida, Excavaciones Arqueológicas, 1996, pp.291-301.

(2002): "Enterramientos infantiles. Restos arqueológicos exhumados en un solar de la zona conocida como los bodegones murcianos", Memoria 6, Mérida, Excavaciones Arqueológicas, 2000, pp.57-78.

MATEOS CRUZ, P. (1995): "Reflexiones sobre la trama urbana de Augusta Emerita.”, Anas, 7, pp. 233-247.

(1995b). "Proyecto de arqueología urbana en Mérida: desarrollo y primeros resultados." Extremadura Arqueológica, IV, pp. 191-215.

(1997): "La arqueología urbana en Mérida: el proceso arqueológico", Memoria 1, Mérida, Excavaciones Arqueológicas, 1994-95, pp. 215-222..

(1999): "Proyecto de Investigación", Foro, 15, Mérida, p.2.

(1999): La Basílica de Santa Eulalia de Mérida. Arqueología y urbanismo, Anejos de AEspA, XIX, Madrid.

(2001). "Augusta Emerita. La investigación arqueológica en una ciudad de época romana." $A E s p A, 74, \mathrm{pp}$. 183-208.
MATEOS CRUZ, P. y MÁRQUEZ PÉREZ, J. (1997): Nuevas estructuras urbanas relacionadas con el Teatro Romano de Mérida: el pórtico de acceso", Memoria 3, Mérida, Excavaciones Arqueológicas, 1997, 301-320.

MAYET, F. (1970): À propos de deus poitiers de Mérida: Valerius Paternus et Lapillius”, Mélanges de la Casa de Velázquez, VI, pp. 1-37.

MOLANO BRÍAS, J.; GIJÓN GABRIEL, E.; MONTALVO FRÍAS, A. Y ALVARADO GONZALO, M. (1991): “Arqueología urbana en Mérida: 1987-1990”, Acta das IV Jornadas Arqueológicas (Lisboa, 1990), Lisboa, pp. $45-55$.

MOLANO BRÍAS, J.; ALVARADO GONZALO, M.; MONTALVO FRÍAS, A. M.; GARCÍA HOZ ROSALES, M. C. y CASTILLO ASTILLO, J. J. (1995): “Avance de las excavaciones en la necrópolis oriental de Augusta Emerita: 'El sitio del Disco' (1988-1990)”, XXI CAN, III, Zaragoza, pp. 1183-1197.ORENO DE VARGAS, B. (1633): Historia de la ciudad de Mérida, Mérida, 1987 ( $3^{\mathrm{a}}$ edición).

MOSQUERA MÜLLER, J. L. (1994): "Excavaciones en el barrio emeritense de Moreria", Revista de Arqueología no 158 , pp.47-48.

MOSQUERA MÜLLER, J. L. y NOGALES BASARRATE, T. (1999): Una ciudad sobre el río. Aquae Aeternae, Badajoz.

NOGALES BASARRATE, T. (1997): El retrato privado en Augusta Emerita, Badajoz.

(2000): Espectáculos en Augusta Emerita, Monografías emeritenses 5. Badajoz.

PALMA GARCÍA, F. (1997): "Las casas romanas intramuros en Mérida. Estado de la cuestión”, Mermoria 3. Mérida Excavaciones Arqueológicas, 1997 pp. 347-365.

(2001): "Ampliación al conocimiento del trazado viario romano de Mérida", Memoria 5, Mérida, Excavaciones arqueológicas, 1999, pp. 225-242.

(2003): "Resultados de la investigación arqueológica realizada durante 2001 en el foro municipal de la colonia Augusta Emerita" en Álvarez Martínez y Nogales Basarrate, Forum coloniae Augustae Emeritae. Templo de Diana, Mérida, pp. 427-445.

RODRÍGUEZ MARTÍN, F. G. (1979): Estudio del Instrumental médico romano existente en Mérida, Tesis de licenciatura mecanografiada, Cáceres.

(1996): Material de un alfar emeritense: paredes finas, lucernas, sigillatas y terracotas, Cuadernos Emeritenses, 11, Mérida. 
(1996b): "Las paredes finas de los talleres emeritenses." Mélanges de la Casa de Velázquez, XXXII, pp. 139179.

(2000): Lucernas romanas del Museo Nacional de Arte Romano (Mérida), Madrid.

(2004): "El paisaje urbano de Augusta Emerita: reflexiones en torno al Guadiana y las puertas de acceso a la ciudad", CuPAUAM (e.p.)

RODRÍGUEZ TEMIÑO, I. (2004): Arqueología urbana en España, Madrid.

SÁNCHEZ-PALENCIA, F. J.; MONTALVO, A. M ${ }^{\mathrm{a}}$. y GIJÓN, E. (2001): "El circo romano de Augusta Emerita", El Circo en Hispania Romana, Madrid, pp. 75-95.

SÁNCHEZ SÁNCHEZ, G. (2001): "Aportaciones a las áreas de enterramiento de época islámica", Memoria 5, Mérida, Excavaciones Arqueológicas, 1999, pp. 2113-224.
SÁNCHEZ SÁNCHEZ, G. y NODAR BECERRA, R. (1997): "Reflexiones sobre las casas suburbanas en Augusta Emerita: estudio preliminar", Memoria 3, Mérida, Excavaciones Arqueológicas, 1997, pp. 367386.

SERRA RÁFOLS, J. de C: (1946): "La Alcazaba de Mérida”, AEspA, 65 (Homenaje a Portugal), pp. 334345

TRILLMICH, W. (1990): "Colonia Augusta Emerita, die Hauptstadt von Lusitanien", Stadtbild und Ideologie. Die Monumentalisierung hispanischer Städte zwischen Republik und Kaiserzeit, München, pp. 299-318.

VELÁZQUEZ JIMÉNEZ, A. (1996): "Don José Álvarez Sáenz de Buruaga. Arqueólogo, Historiador, Bibliófilo y Humanista", REE, LII-2, Badajoz, pp. 349-354.

(2002): Repertorio de bibliografía arqueológica emeritense II. Emerita 2000, Cuadernos Emeritenses, 19, Mérida. 